\title{
Delinquent Behavior, Future Divorce or Nonmarital Childbearing, and Externalizing Behavior Among Offspring: A 14-Year Prospective Study
}

\author{
Robert E. Emery and Mary Waldron \\ University of Virginia
}

\author{
Katherine M. Kitzmann \\ University of Memphis
}

\author{
Jeffrey Aaron \\ University of Virginia
}

\begin{abstract}
In a longitudinal study of a national sample, more externalizing behavior problems were found among 222 children from never-married and 142 children from divorced families than among 840 children from married families. However, delinquent behavior reported when future mothers were single, childless adolescents prospectively predicted their future marital status and behavior problems among their offspring 14 years later. Maternal history of delinquent behavior accounted for much, but not all, of the relationship between marital status and children's externalizing behavior. Divorce and nonmarital childbirth do not occur at random, and these findings demonstrate that marital status is predicted by individual characteristics as well as by demographic factors. These findings highlight the importance of cautiously interpreting the much-discussed correlation between marital status and children's behavior problems.
\end{abstract}

Much research has been conducted on the psychological adjustment of children who are born outside of marriage or whose parents divorce. Research has been stimulated by the dramatic increases in the rates of both divorce and nonmarital childbirth in the United States since the 1960s. Rates have stabilized and are slowly showing a downward trend, but about $40 \%$ of all children born to married parents still are predicted to experience their parents' divorce (U.S. Census Bureau, 1992), and about $25 \%$ of all children in the United States

Robert E. Emery and Mary Waldron, Department of Psychology, University of Virginia; Katherine $\mathbf{M}$. Kitzmann, Department of Psychology, University of Memphis; Jeffrey Aaron, Department of Pediatrics, University of Virginia.

We acknowledge the support of the Harry Frank Guggenheim Foundation and the University of Virginia Center for Children, Families, and the Law in the preparation of this article.

Correspondence concerning this article should be addressed to Robert E. Emery, Department of Psychology, Gilmer Hall, University of Virginia, Charlottesville, Virginia 22903. Electronic mail may be sent to ree@virginia.edu. currently are born outside of marriage (National Center for Health Statistics, 1997). Although the demographics are clear, vigorous debates have continued about whether research demonstrates that the increased risk for psychological problems among children from divorced and nevermarried families is modest (e.g., Amato \& Keith, 1991) or unexpectedly large (e.g., Wallerstein \& Blakeslee, 1989).

A series of studies on divorce has raised an even more basic question about the appropriate interpretation of the increased risk found among children from single-parent families: Are obtained differences consequences of divorce or nonmarital childbirth, or are they attributable to nonrandom selection into family status? The vast majority of studies of the putative consequences of divorce for children (including longitudinal studies) have assessed families for the first time after divorce. However, a few recent, prospective studies indicate that many of the psychological problems found among children and adolescents from divorced versus married families were present before the marital separation (Block, Block, \& Gjerde, 1986; Cherlin et al., 1991; Doherty \& Needle, 1991; 
Elliott \& Richards, 1991). ${ }^{1}$ Thus, at least some of the psychological problems found among children from divorced families cannot be caused by divorce. Rather, a significant amount of variance in the relationship between divorce and children's behavior problems must result from selection factors that predispose families both to divorce and to having troubled children. Potential selection variables include demographic background characteristics (such as poverty), family processes (such as marital conflict), and parental behavior or personality characteristics (such as antisocial behavior), the focus of this research.

Unlike divorce, it is impossible to study children's adjustment prospectively in attempting to document the consequences of nonmarital childbirth. In this case as well, however, a compelling alternative to the consequences hypothesis is that selection (partially) accounts for differences in the adjustment of children from married and never-married families.

Parental antisocial behavior is a good candidate among a host of behavioral and personality variables that might lead to nonrandom selection into single-parent family status and thereby explain the association between divorce or nonmarital childbirth and children's behavior problems. This is the case because various evidence indicates that (a) disruptive and delinquent behavior among youth increases the risk for future nonmarital childbirth, marital separation, and divorce (Caspi, Elder, \& Bem, 1987); (b) a history of externalizing or antisocial behavior among parents is associated with increased externalizing behavior among children (DiLalla \& Gottesman, 1990); and (c) externalizing problems are among the most prevalent behavior problems found among children from divorced or never-married families (Amato \& Keith, 1991; Emery, 1999).

In fact, a few investigators have examined whether parental antisocial behavior (measured after divorce) accounts for the relationship between divorce and children's adjustment problems. (We are aware of no such studies of nonmarital childbirth.) Lahey and colleagues (1988) found that parents' antisocial personality disorder fully explained the relationship between divorce and children's conduct disorder among a group of 62 boys seen at a clinic. Capaldi and Patterson (1991) similarly reported that mothers' antisocial behavior fully ac- counted for the relationship between marital transitions and adjustment problems in a community sample of 203 sixth-grade boys from high-crime neighborhoods. In this study, the relationship between parents' antisocial behavior and children's behavior problems was explained, in turn, by inadequate parental involvement (Capaldi \& Patterson, 1991). In a similar analysis, Simons and Chao (1996) found that mothers' antisocial traits were associated with parental divorce in a community sample of 216 boys and 247 girls, but inept parenting largely accounted for the relationship of both divorce and mothers' antisocial behavior with early-adolescence delinquent behavior. The one exception was that, for girls only, a small but statistically significant direct relationship between mothers' antisocial traits and delinquency remained even after inept parenting was entered into the model. Somewhat different results were reported by Rutter (1971) in a study of unhappy marriages among community samples of children living in London and on the Isle of Wight. Parental personality disorder did not account for the risk for children's conduct disorder associated with marital distress, but the interaction between personality disorder and marital unhappiness approached statistical significance in predicting increased conduct problems among adolescents.

The possibility that parental behavioral or personality characteristics explain the relationship been divorce and children's behavior problems also has been suggested by recent studies examining genetic contributions to divorce. In the first of such studies, McGue and Lykken (1992) examined the divorce status of 1,516 same-sex monozygotic (MZ) and dizygotic (DZ) twin pairs, and they found that the concordance for divorce was significantly higher in $\mathrm{MZ}$ than in $\mathrm{DZ}$ twins. Because $\mathrm{MZ}$ twins share $100 \%$ of their segregating genes and $\mathrm{DZ}$ twins share, on average, only $50 \%$, significant MZ-DZ differences strongly suggest that genetic factors influence the familial transmission

\footnotetext{
${ }^{1}$ Recent research has found that predivorce factors explain less variance in the adjustment of young adults from divorced families (Chase-Lansdale, Cherlin, \& Kiernan, 1995; Cherlin, Chase-Lansdale, \& McRae, 1998), but many of the differences in the adjustment of school-age children from divorced and married families have been found to predate the marital separation.
} 
of divorce. In an attempt to identify one mechanism through which genetic factors contribute to divorce risk, Jockin, McGue, and Lykken (1996) examined correlations between marital status and personality characteristics for a subset of the twins included in McGue and Lykken's (1992) analysis. The investigators found that correlations between twin personality and cotwin divorce were significantly higher for $M Z$ twins than for $D Z$ twins, suggesting that a portion of the genetic contribution to divorce risk is accounted for by individual personality characteristics.

As a group, these studies underscore the importance of including individual behavioral and personality characteristics, especially markers of antisocial behavior, and familial, social, and demographic factors in examinations of nonrandom selection into divorce and in attempts to explain the relationship between parental divorce and adjustment difficulties among children. This study extends this line of investigation by prospectively testing whether maternal delinquent activities predict future divorce and children's behavior problems. This study also extends past research by, for the first time, conducting a similar set of analyses for children born outside of marriage.

Maternal delinquent behavior actually may contribute to the relationship between marital status and children's externalizing behavior in several different and theoretically interesting ways. Four alternative models are presented in Figure 1. Model 1 is the approach implicit in much of the divorce literature. It is termed the consequences model, as it contains no relationship between maternal delinquent activities and either future marital status or children's externalizing behavior. Models 2, 3, and 4 all reflect selection into alternative marital statuses, but they present different accounts of how maternal delinquent behavior contributes to the relationship between marital status and children's externalizing behavior. Model 2 is termed the mediation model, as the relationship between maternal delinquent behavior and children's externalizing behavior is indirect and fully accounted for by marital status. Model 3 is termed the spurious model, as the relationship between marital status and children's externalizing behavior becomes nonsignificant when maternal delinquent behavior is added to the equation. Finally, Model 4 is termed the multiple-pathways model, as maternal delin-
Consequences Model

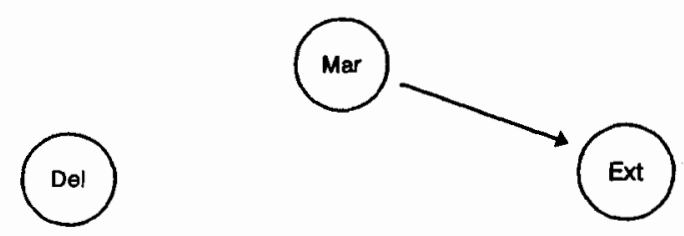

Mediation Model

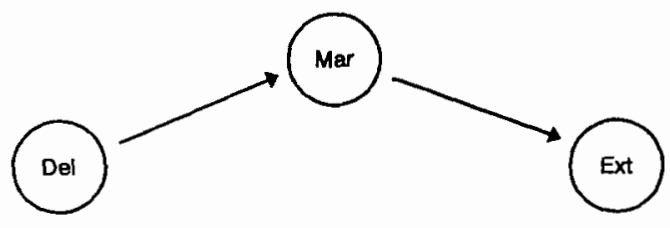

Spurious Model

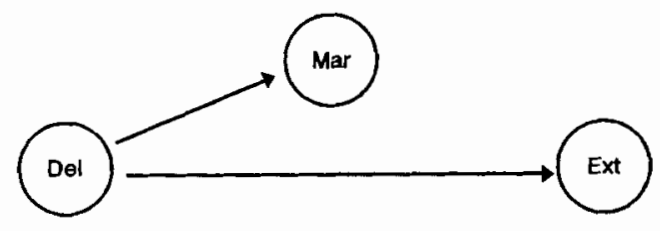

Multiple Pathways Model

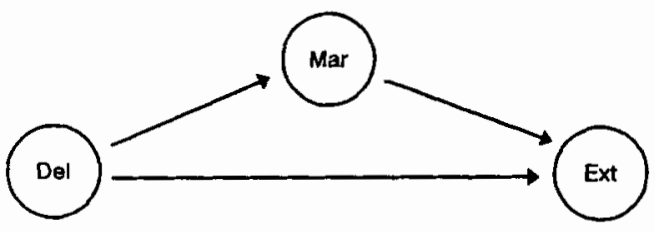

Figure 1. Four models of possible relationships among female adolescents' delinquent behavior, their future marital status, and their children's subsequent externalizing behavior. Del = delinquency; Mar = marital status (married versus divorced or never married); Ext $=$ children's externalizing behavior.

quent behavior has both direct and indirect (through marital status) relationships with children's externalizing behavior.

The primary purpose of this study was to evaluate these four models. Data on 1,204 mothers and children were drawn from the National Longitudinal Survey of Youth (NLSY)-Child Sample, an ongoing study of a national sample of mothers and their children (Center for Human Resources Research, 1995). 
More specifically, delinquent behaviors as selfreported in 1980 (when the future mothers were 15 to 22 years old) were used to predict (a) divorce or nonmarital childbearing between 1981 and 1993 and (b) behavior problems in 1994 among the children born to the women. We hypothesized that mothers' delinquent activities would predict their marital status and externalizing behavior among their children as many as 14 years into the future. In contrast to Lahey et al. (1988) and Capaldi and Patterson (1991), however, we hypothesized that Model 4 would receive the strongest support. That is, we expected mothers' delinquent behavior to partially, but not fully, explain the relationship between marital status and children's behavior problems. This prediction was based on considerations about the importance of parental antisocial behavior together with the extensive literature indicating that a number of family and demographic factors (e.g., interparental conflict, parenting difficulties, and economic hardship) also are related to the risk for adjustment problems among children from divorced or never-married families (Emery, 1999). This last observation also led to the hypothesis that the relationship between marital status and children's externalizing behavior would be reduced but would remain significant after the addition of demographic controls in tests of the four models.

\section{Method}

\section{Sample}

The NLSY began with the assessment of a nationally representative sample of 12,686 young men and women 14 to 21 years old as of January 1, 1979. Assessments have continued yearly. Measures focus primarily on demographics, education, and employment, as the study began as a Labor Department survey of entry into the workforce. However, various psychological measures have been given to the survey participants at different points in time. Of particular relevance to this analysis, the 1980 survey included a self-report measure of delinquent behavior (discussed below).

By 1986, 3,322 women in the NLSY sample had given birth to 5,876 children, and these children (children of the NLSY) were administered a variety of measures of their social, psychological, and academic functioning. Assessments of the children of the NLSY have continued biennially. In 1994, the assessment year used for this analysis, data were collected on 7,089 children. Because of sampling methods, the children of the NLSY sample is heavily weighted toward young parents and children, meaning that members of minority groups, lower-income families, and teenage mothers are overrepresented because of fertility patterns. Finally, the children of the NLSY sample data are indexed according to children, not families, so more than one child per family may be represented in the data.

A number of selection criteria were used to identify a subsample of the entire 1994 data set for this analysis. First, in order to ensure the statistical independence of the child data, only one child per family (the oldest) was selected for inclusion in the analysis. This criterion reduced the sample size from 7,089 to 4,599 . Second, children had to be 4 years old or older, the cutoff for administering the measure of child externalizing behavior, the Behavior Problems Index (BPI; discussed below). This criterion reduced the sample size from 4,599 to 4,261. Third, mothers had to be (a) never married, (b) married and still in their first marriage, or (c) divorced for the first time and not remarried as of 1994 . This criterion reduced the sample size from 4,261 to 2,606 . The loss of participants at this stage was attributable primarily to missing marital status data $(n=1,134)$, one remarriage $(n=369)$, or muitiple marital transitions $(n=152)$. Fourth, children from intact or divorced families were included only if they were born in wedlock and, for divorced families, prior to the divorce. This criterion reduced the sample size from 2,606 to 1,994 . Finally, families were included only if they had complete data on the three major measures of interest: marital status, mother's 1980 delinquency, and the BPI. This criterion reduced the sample size from 1,994 to 1,204 . On the basis of these multiple selection criteria, 840 married, 142 divorced, and 222 never-married families were identified in the 1994 data set. ${ }^{2}$

${ }^{2}$ Analyses indicated that the marital status selection criteria biased the subsample slightly. In comparison to families who did not meet criteria, families who met selection criteria were more likely to have older mothers with older children who were born to younger mothers. Selected (versus unselected) families also were more likely to be White and to have slightly lower delinquency and BPI scores but were also more likely to be living in poverty in 1980 and 1994. The complete data selection criteria introduced even smaller selection effects. Selected (versus unselected) families were more likely to have older mothers with older children who were born to younger mothers but were also more likely to be non-White and to not be living in poverty. It should be noted that all subsample selection effects were small in magnitude and, more generally, that no claim is made that either the subsample used here or the children of the NLSY sample is a nationally 
Table 1

Demographic Characteristics of the Sample

\begin{tabular}{lccccccc}
\hline & \multicolumn{2}{c}{$\begin{array}{c}\text { Married } \\
(n=840)\end{array}$} & & \multicolumn{2}{c}{$\begin{array}{c}\text { Divorced } \\
(n=142)\end{array}$} & \multicolumn{2}{c}{$\begin{array}{c}\text { Never married } \\
(n=22)\end{array}$} \\
\cline { 2 - 3 } \multicolumn{1}{c}{ Characteristic } & $M$ & $S D$ & & $M$ & $S D$ & $M$ & $S D$ \\
\hline Mother's age & 33.2 & 2.2 & 32.7 & 2.2 & 32.1 & 1.9 \\
Age at first marriage & 21.8 & 2.8 & 20.6 & 2.7 & & \\
Age at first divore & & & 28.4 & 3.5 & & \\
Age at first childbirth & 24.2 & 3.3 & 22.4 & 3.2 & 21.7 & 3.2 \\
Age of child & 8.9 & 2.9 & 10.3 & 2.7 & 10.9 & 2.9 \\
\% Boys & 53 & & 51 & & 50 & \\
\% Non-White & 34 & & 47 & & 89 & \\
\% Living in poverty in 1980 & 14 & & 22 & & 48 & \\
\% Living in poverty in 1994 & 7 & & 27 & & 47 & \\
\hline
\end{tabular}

Note. Ages are given in years.

Demographic data describing the sample used in this study are presented in Table 1, separately for married, divorced, and never-married families. Scheffé comparisons revealed several significant differences between marital status groups. Married and divorced mothers were significantly older in 1994 than never-married mothers, $F(2,1204)=22.90, p<$ .001 , and married mothers were significantly older at first marriage than divorced mothers, $F(2,1204)=$ $21.12, p<.001$. Married mothers were also significantly older than both divorced and nevermarried mothers at first childbirth, and divorced mothers were significantly older than never-married mothers at first childbirth, $F(2,1204)=63.47, p<$ .001 . Consistent with these differences, children of never-married and divorced mothers were significantly older in 1994 than children of married mothers, $F(2,1204)=32.86, p<.001$. Significant group differences were also found for 1980 and 1994 poverty status and race. Married mothers were least likely to have lived in poverty in 1980 (14\%), followed by divorced mothers $(22 \%)$ and nevermarried mothers $(48 \%), \chi^{2}(2, N=1,135)=113.0$, $p<.001$. A similar pattern was found for 1994 poverty status, $\chi^{2}(2, N=951)=168.97, p<.001$. Finally, never-married mothers were more likely to be non-White $(89 \%)$, followed by divorced mothers $(47 \%)$ and married mothers $(34 \%), \chi^{2}(2$, $N=1,204)=213.82, p<.001$.

These demographic differences raise conceptual and practical problems for data analysis. Any differences found between the marital status groups might be attributable to other demographic characteristics; thus, it would be desirable to control for

representative sample of children. However, both the children of the NLSY sample and the subsample used here (see Table 1) are large and diverse samples. demographic variables statistically. At the same time, variables such as a history of poverty or a younger age at first childbirth are an inherent part of the experience of divorce and nonmarital childbirth, and controlling for them can create artificial statistical models. Because of these complexities, all analyses were run both with and without controls for differences in background variables. For the analyses with controls, all of the variables listed in Table 1 were included, with the exception of 1994 poverty. Current poverty status was excluded because it is most clearly a consequence of family status.

\section{Measures}

Marital status and other demographic measures were obtained from structured participant interviews. In addition, the following two self-report measures were obtained.

Delinquency self-report. Maternal delinquent activities were assessed on a 30-item self-report measure administered to the NLSY participants in 1980. On the basis of research on self-report measures of delinquency (Hindelang, Hirschi, \& Weiss, 1981; Huizinga \& Elliott, 1986), we used conceptual and empirical criteria to group 19 of the items into four subscores measuring (a) delinquency (e.g., fought at school or work), (b) drug usage (e.g., smoked marijuana), (c) serious criminality (e.g., broke into a building), and (d) contact with the criminal justice system (e.g., was charged with an illegal act). A total delinquent behavior score also was created by summing all 19 items. Because no consistent differences pertaining to our hypotheses were found among the subscores, only the total delinquent behavior score was used in the analyses presented here. The total score included all 19 items and had an alpha coefficient of .70 for the sample. 
Table 2

Analyses of Variance of Children's Externalizing Behavior and Mothers' Delinquency by Marital Status

\begin{tabular}{|c|c|c|c|c|c|c|c|c|}
\hline \multirow[b]{2}{*}{ Variable } & \multicolumn{2}{|c|}{ Married (I) } & \multicolumn{2}{|c|}{ Divorced (D) } & \multicolumn{2}{|c|}{ Never married $(\mathrm{N})$} & \multirow[b]{2}{*}{$F$} & \multirow{2}{*}{$\begin{array}{l}\text { Scheffé test } \\
\text { result }\end{array}$} \\
\hline & $M$ & $\widehat{S D}$ & $M$ & $\overline{S D}$ & $M$ & $\widehat{S D}$ & & \\
\hline Mothers' delinquen & 2.34 & 1.64 & 3.02 & 2.32 & 18 & .22 & $22.75^{* * *}$ & $\mathrm{D}, \mathrm{N}>\mathrm{I}$ \\
\hline . & 6.90 & 5.66 & 8.42 & 6.26 & 8.74 & 6.32 & $11.06^{* * *}$ & $\mathrm{D}, \mathrm{N}>\mathrm{I}$ \\
\hline
\end{tabular}

$* * * p<.001$.

Child externalizing behavior. Child externalizing behavior was measured on the Externalizing Scale of the BPI, a 28-item parent-report measure developed by Peterson and Zill (1986) and based on Achenbach's Child Behavior Checklist (Achenbach \& Edelbrock, 1985). The BPI contains six subscales derived through factor analysis (antisocial, anxiousdepressed, hyperactive, stubborn-parental conflicting, social withdrawal, and immature dependency) and trichotomous factor scales reflecting externalizing, internalizing, and total problem behaviors. Because the individual subscales have a small number of items and lower reliability and we were interested in child behavior problems most strongly associated with marital status (Amato \& Keith, 1991; Emery, 1999) and maternal delinquent activities (DiLalla \& Gottesman, 1990), the Externalizing Scale alone was analyzed. ${ }^{3}$ The Externalizing Scale contains items reflecting "acting-out" behavior (e.g., cheats or tells lies, has trouble getting along with other children, or has a very strong temper and loses it easily). Peterson and Zill (1986) report moderate alpha coefficients for the BPI subscales, ranging from .54 to .76 .

\section{Results}

Data analysis was conducted as follows. First, in order to provide a straightforward test of expected group differences, analyses of variance (ANOVAs) were conducted to compare the three marital status groups in terms of (a) children's externalizing scores and (b) mothers' delinquency. Second, bivariate correlations were calculated between the major demographic variables and (a) children's externalizing behavior and (b) mothers' delinquency. Third, regression analysis was used to test the four models (see Figure 1) of the prospective interrelationships among mothers' delinquent activity, marital status, and children's externalizing behavior. Finally, the relationships among these three variables were examined categorically by use of upper-quartile cutoff scores on the delinquency and BPI scales to define extreme groups.

\section{Mean Differences by Marital Status}

Means and standard deviations for mothers' delinquent activities and children's externalizing behavior for the three marital status groups are presented in Table 2, together with ANOVA results. As expected, mean levels of externalizing behavior were significantly higher for children from both divorced and never-married families than for children from married families, although the effect sizes were small (as expected). The mean externalizing behavior scores were not significantly different for children from divorced and never-married families.

As predicted, mean levels of delinquent behavior were significantly higher for both divorced and never-married mothers than for married mothers. Effect sizes were moderate for mothers' delinquent activities during adolescence. Differences between divorced and nevermarried mothers on the delinquency measure were not significant.

\section{Relationships With Demographic Variables}

Bivariate correlations between the major demographic variables and mothers' delinquency and children's behavior problems are presented in Table 3. Mothers' delinquent

${ }^{3}$ All analyses for externalizing behavior reported in this article also were repeated for the BPI Internalizing Scale. The results were essentially the same as for the BPI Externalizing Scale and thus are not reported here. The pattern of results may reflect similar effects for externalizing and internalizing, but they also are a function of measurement. The Internalizing Scale and the Externalizing Scale of the BPI were highly correlated in this sample, $r=.71$, $N=1,204, p<.001$. 
Table 3

Correlations Between Demographic Variables and Mothers' Delinquency and Children's Externalizing Behavior

\begin{tabular}{lcc}
\hline \multicolumn{1}{c}{ Variable } & $\begin{array}{c}\text { Mothers' } \\
\text { delinquency } r\end{array}$ & $\begin{array}{c}\text { Children's } \\
\text { externalizing behavior } r\end{array}$ \\
\hline Mother's age & $-.12^{* * *}$ & $-.06^{*}$ \\
Mother's age at first childbirth & $-.08^{* *}$ & $-.13^{* * *}$ \\
White/non-White & .03 & $.08^{* *}$ \\
Poverty in $1980^{\mathrm{b}}$ & $.09^{* * *}$ & .05 \\
Poverty in 1994 & $.13^{* * *}$ & $.18^{* * *}$ \\
Child's age & .02 & $.11^{* * *}$ \\
Child's genderc & -.02 & $-.11^{* * *}$ \\
\hline
\end{tabular}

Note. $n=951$ for 1980 poverty and $n=1,134$ for 1994 poverty because of missing data. $n=1,204$ for all other demographic variables.

${ }^{\mathrm{a}} 1=$ White, $2=$ non-White. ${ }^{\mathrm{b}} 1=$ poor, $2=$ nonpoor. ${ }^{\mathrm{c}} 1=$ boys, $2=$ girls.

${ }^{*} p<.05 .{ }^{* *} p<.01 .{ }^{* * *} p<.001$.

behavior during adolescence was inversely related to age, reflecting the well-documented finding that delinquent activities decrease with age (Moffit, 1993). (Recall that the women were 15 to 22 years old in 1980 when they completed the delinquency measure.) Mothers' delinquent behavior also was positively correlated with age at first childbirth and poverty status in both 1980 and 1994, indicating that increased delinquent activities among female adolescents is related to childbirth at a younger age and to both concurrent and future poverty.

Mothers' current age and age at first childbirth were both related to children's externalizing behavior, such that younger mothers and mothers who were younger at first childbirth (many were teenagers) had children who later exhibited more behavioral difficulties. More externalizing behavior problems also were found among children currently living in poverty, among older children, among boys, and among non-White children.

\section{Testing Alternative Models}

Multiple regression was used to test the four alternative models outlined in Figure 1. All analyses were conducted twice, once with and once without controls for all the background characteristics listed in Tables 1 and 3, excluding 1994 poverty. For analyses that included the background controls, mean scores were substituted when the variable was missing in order to retain the same sample sizes for the two sets of analyses. (Complete data were available for all control variables except 1980 poverty, for which there were 69 missing cases.) Results for models comparing married versus divorced families are presented in Table 4, and findings for married versus never-married families are summarized in Table 5.

Married versus divorced families. As established by the ANOVAs, children's externalizing behavior was significantly associated with divorced family status in the regression analyses,

Table 4

Standardized Regression Coefficients for Alternative Models for Married and Divorced Families

\begin{tabular}{|c|c|c|c|}
\hline \multirow[b]{2}{*}{ Model } & \multirow[b]{2}{*}{ Relationship } & \multicolumn{2}{|c|}{ Regression coefficient ( $n=982)$} \\
\hline & & Without controls & With controls \\
\hline 1 & Marital status to children's externalizing behavior $\left(\beta_{23}\right)$ & $.09 * *$ & $.07 *$ \\
\hline 2 & Delinquency to marital status ${ }^{a}\left(\beta_{12}\right)$ & $.14 * * *$ & $.13 * * *$ \\
\hline 3 & Delinquency to children's externalizing behavior $\left(\beta_{13.2}\right)$ & $.11 * * *$ & $.11^{* * *}$ \\
\hline 4 & Marital status to children's externalizing behavior $\left(\beta_{23.1}\right)$ & $.08^{* *}$ & .05 \\
\hline
\end{tabular}

$1=$ married; $2=$ divorced.

$* p<.05 . \quad * * p<.01 . \quad * * * p<.001$. 
Table 5

Standardized Regression Coefficients for Alternative Models for Married and Never-Married Families

\begin{tabular}{clcc}
\hline & & \multicolumn{2}{c}{ Regression coefficient $(n=1,062)$} \\
\cline { 3 - 4 } Model & \multicolumn{1}{c}{ Relationship } & Without controls & With controls \\
\hline 1 & Marital status to children's externalizing behavior $\left(\beta_{23}\right)$ & $.13^{* * *}$ & $.08^{*}$ \\
2 & Delinquency to marital status $\left(\beta_{12}\right)$ & $.19^{* * *}$ & $.17^{* * *}$ \\
3 & Delinquency to children's externalizing behavior $\left(\beta_{13.2}\right)$ & $.14^{* * *}$ & $.15^{* * *}$ \\
4 & Marital status to children's externalizing behavior $\left(\beta_{23.1}\right)$ & $.10^{* *}$ & .05 \\
\hline
\end{tabular}

$\mathrm{a}_{1}=$ married; $2=$ never-married.

${ }^{*} p<.05 . \quad{ }^{* *} p<.01 . \quad{ }^{* * *} p<.001$.

even after controlling for demographic factors (see Table 4). As predicted by all three selection models, however, female adolescents' delinquent activities in 1980 significantly predicted their divorced marital status in 1994, and control variables had little effect on this relationship. Contrary to the predictions of the mediation model, mothers' delinquent activities during adolescence predicted externalizing behavior problems among their children, and the data changed little in magnitude even when mothers' current marital status and other demographic factors were taken into account statistically. ${ }^{4}$

Consistent with the multiple-pathways model, whether mothers were married or divorced in 1994 significantly predicted concurrent externalizing behavior among their children, even when mothers' delinquent behavior was taken into account. However, the magnitude of the standardized beta value was almost halved and became nonsignificant when demographic variables were statistically controlled together with mothers' delinquent behavior (see Table 4). Thus, support was found for both the multiple-pathways model (analyses without control variables) and the spurious model (analyses with control variables). Finally, it should be noted that the interaction of mothers' delinquent behavior and marital status did not add significantly to the prediction of children's externalizing behavior.

Married versus never-married families. Analyses comparing married and never-married families closely matched those for divorce; in fact, a greater proportion of variance was accounted for in these analyses. As expected, children's externalizing behavior was related to never-married family status in the regression analyses, even after controlling for demographic factors (see Table 5). Again, however, female adolescents' delinquent activities in 1980 significantly predicted their never-married marital status in 1994, and the relationship was only slightly attenuated by the inclusion of control variables. Contrary to the predictions of the mediation model, mothers' delinquent activities during adolescence predicted externalizing behavior problems among their children, even when marital status and demographic factors were taken into account statistically. ${ }^{5}$

Consistent with the multiple-pathways model, whether mothers were married or never married in 1994 significantly predicted concurrent externalizing behavior among their children, when mothers' delinquent behavior was taken into account. As with divorce, however, the beta value was reduced notably and became nonsignificant when demographic factors were controlled together with mothers' delinquent behavior (see Table 5). Thus, support was again found for both the multiple-pathways model (analyses without control variables) and the spurious model (analyses with control variables). Finally, it should be noted that the interaction of mothers' delinquent behavior and marital status did not add significantly to the prediction of children's externalizing behavior.

\footnotetext{
${ }^{4}$ For the direct path between delinquency and children's externalizing behavior (without controlling for marital status), $\beta_{13}=.12$ and $p<.001$ without demographic controls and $\beta_{13}=.14$ and $p<.001$ with demographic controls.

${ }^{5}$ For the direct path between delinquency and children's externalizing behavior (without controlling for marital status), $\beta_{13}=17$ and $p<.001$ without demographic controls and $\beta_{13}=.16$ and $p<.001$ with demographic controls.
} 


\section{Categorical Analysis of Extreme Groups}

In order to further test the relationships among delinquent behavior, marital status, and children's externalizing problems, a series of categorical analyses were conducted with the three marital status variables and extreme groups on the delinquency and externalizing measures. The continuous measures were made categorical by cutting off both the delinquency and the externalizing behavior measures at the upper quartile.

As determined by these analyses, scoring in the upper quartile on the delinquency measure in 1980 significantly increased the future risk for both nonmarital childbirth, $\chi^{2}(1, N=1,062)=$ $25.09, p<.001$, and divorce, $\chi^{2}(1, N=982)=$ $5.04, p<.05$, in comparison to childbirth in a stable marriage. Female adolescents who scored in the upper quartile on the delinquent behavior measure were $50 \%$ more likely to become divorced and almost twice as likely to bear a child outside of marriage as other female adolescents.

Scoring in the upper quartile on the delinquency measure also significantly increased the risk of having a child who, 14 years later, scored in the upper quartile on the measure of externalizing behavior, $\chi^{2}(1, N=1,204)=$ $11.99, p<.001$. Across the three marital status groups, female adolescents who scored in the upper quartile on the delinquency measure were $50 \%$ more likely than other female adolescents to have a child who scored in the upper quartile on the BPI Externalizing Scale.

Both divorced mothers, $\chi^{2}(1, N=982)=$ $7.69, p<.01$, and never-married mothers, $\chi^{2}(1$, $N=1,062)=8.38, p<.01$, were significantly more likely to have a child who scored in the upper quartile on externalizing. Children of divorced or never-married mothers both were about $50 \%$ more likely to score in the upper quartile on externalizing than were children of married mothers. Finally, the interaction between marital status and mothers' history of delinquency in predicting children's behavior problems was not significant, as determined by logistic regression analyses.

\section{Discussion}

As hypothesized, the self-reported delinquent behavior of female adolescents measured in 1980 significantly predicted their family status measured in 1994. Female adolescents scoring in the upper quartile on delinquent activities in 1980 were nearly twice as likely as their more conforming counterparts to be never-married parents and 50\% more likely than their more conforming counterparts to be divorced 14 years later. Such results may not terribly surprising from the perspective of the delinquency literature, as problem behavior among female adolescents is defined, in part, by early sexuality, promiscuity, and troubled romantic relationships. However, the results are more notable from the perspective of the literature on marital status, which has overwhelmingly emphasized social, demographic, and cultural predictors of family status rather than individual behavioral and personality factors. As such, the findings highlight the straightforward but often overlooked point that behavioral and personality variables contribute to risk for nonmarital childbirth and divorce, even in a society in which both family statuses are very common.

This study also indicated that problem behavior during adolescence predicts externalizing behavior among future offspring. When the three marital status groups were combined, mothers who scored in the upper quartile on the measure of delinquent behavior were about $50 \%$ more likely to have a child who scored in the upper quartile on the measure of externalizing behavior 14 years later.

When we tested alternative models of the relationship among delinquency, future marital status, and children's externalizing behavior (see Figure 1), both the consequences and the mediation models were rejected, the latter because the direct path between mothers' delinquent behavior and children's externalizing behavior (14 years later) remained significant in all analyses. The data were less clear with regard to the spurious and the multiple-pathways models. In contrast to the predictions of the spurious model, accounting for mothers' delinquent behavior in regression analyses reduced the significant relationship between marital status and children's externalizing behavior only modestly when demographic control variables were omitted from the regressions. In contrast to the predictions of the multiple-pathways model, however, the partial correlation was halved and was no longer significant when demographic control variables were introduced. These correlated demographic factors clearly contribute to 
the increase in children's externalizing behavior in single-parent families. Still, one can argue that statistical controls for demographic variables create artificial models of the real world, as a history of poverty and childbearing at an early age are a part of the experience of many never-married and divorced mothers. In any case, it is clear that the path linking marital status and children's externalizing behavior was not fully accounted for by maternal delinquent behavior alone. This finding contrasts with some other analyses of divorce (Capaldi \& Patterson, 1991; Lahey et al., 1988) and, to our knowledge, this study is the first such analysis of nonmarital childbearing.

A few other aspects of our findings should be noted briefly. Only a small proportion of variance in children's behavior problems was accounted for by marital status. Although this modest relationship contrasts with the conclusions of some experts (e.g., Wallerstein \& Blakeslee, 1989), it is in line with the results of a meta-analysis of 94 studies of children and divorce (Amato \& Keith, 1991). At the same time, it should be noted that children whose parents were divorced or never married were about $50 \%$ more likely to score in the upper quartile on the BPI as were children whose parents were married. Thus, as with other research (McLanahan \& Sandefur, 1994), modest mean differences in children's behavior problems associated with marital status translate into differences in extreme groups that take on clinical and social significance (Emery, 1999).

Despite the large and diverse sample, the reliable measurement of constructs, and the prospective analysis over a period of 14 years, some limitations of our results should be noted. The absence of data on fathers' antisocial behavior is a notable weakness, both in terms of predicting aggression among children and in terms of examining patterns of assortative mating. It should be noted, however, that logistics would make a comparable, prospective analysis of fathers' delinquency impossible. There would be no way of knowing (and therefore assessing) who was to become a female adolescent's coparent or husband between the time when the female adolescents completed the delinquency measure and the time when they assessed their children's behavior 14 years later. Questions also can be raised about the limitations introduced by the use of relatively brief measures of delinquency and of children's externalizing behavior; however, such measures are well accepted in both areas of assessment (Achenbach, McConaughy, \& Howell, 1987; Hindelang, Hirschi, \& Weiss, 1981; Huizinga \& Elliott, 1986). The use of the same rater of mothers' delinquency and children's externalizing behavior also is a limitation, although the two reports were separated by 14 years. The use of assessments from a single point in time also can be questioned, especially because adolescent delinquent activities often are transient (Moffit, 1993) and because the ratings were obtained when the future mothers were of different ages. The association between parents' and children's antisocial behaviors is stronger when antisocial behavior is assessed during developmental periods, when transient rule violations are less common (e.g., early childhood and adult life; DiLalla \& Gottesman, 1990). Partially because of developmental issues, the delinquency measure is best viewed as a limited measure of the broader construct of mothers' antisocial behavior that, if measured more fully, might prove to be a stronger predictor of marital status, children's externalizing behavior, or both.

Although assessment limitations may have attenuated the magnitude of the relationship's obtained, measurement problems are unlikely explanations of the overall pattern of results. Our findings thus underscore the important observation that marital status does not occur at random. Maternal delinquent activities during adolescence and, likely, other indexes of individual parental behavior and personality both predict future single-parent family status and account for much of the relationship between family status and externalizing behavior among children. However, the findings do not support suggestions that the link between divorce and children's behavior problems is fully accounted for by parental antisocial behavior. More generally, the results suggest that the correlation between children's environment and their parents' behavior or personality--which typically is interpreted in behavior genetic terms (Scarr \& McCartney, 1983)--sometimes may lead to the environmental mediation of individual characteristics across the generations. That is, parents with certain behavioral styles may "create" environments for their children, and together with-or apart from-genetically determined 
behavioral or personality characteristics, these nonrandom environments may help to promote the development of phenotypically similar behaviors in parents and children.

\section{Implications for Application and Public Policy}

Our findings also suggest that practitioners and policymakers carefully interpret the correlation between marital status and children's behavior problems. The increased risk for psychological problems among children associated with nonmarital childbearing and divorce is partially accounted for by concurrent demographic controls. More to the point of our study, this relationship also may be partially explained by parents' individual behavior and personality characteristics. More specifically, our analysis indicated that notable proportions of the putative consequences of divorce and nonmarital childbearing for children's externalizing behavior were accounted for by maternal delinquent activities 14 years in the past.

\section{References}

Achenbach, T. M., \& Edelbrock, C. (1985). Manual for the Child Behavior Checklist. Burlington: University of Vermont.

Achenbach, T. M., McConaughy, S. H., \& Howell, C. T. (1987). Child/adolescent behavioral and emotional problems: Implications of cross-informant correlations for situational specificity. Psychological Bulletin, 101, 213-232.

Amato, P. R., \& Keith, B. (1991). Parental divorce and the well-being of children: A meta-analysis. Psychological Bulletin, 110, 26-46.

Block, J. H., Block, J., \& Gjerde, P. (1986). The personality of children prior to divorce: A prospective study. Child Development, 57, 827-840.

Capaldi, D. M., \& Patterson, G. R. (1991). Relation of parental transitions to boys' adjustment problems: I. A linear hypothesis. II. Mothers at risk for transitions and unskilled parenting. Developmental Psychology, 27, 489-504.

Caspi, A., Elder, G. H., \& Bem, D. J. (1987). Moving against the world: Life-course patterns of explosive children. Developmental Psychology, 23, 308-313.

Center for Human Resources Research. (1995). National Longitudinal Study handbook. Columbus: $\mathrm{OH}$ : Author.

Chase-Lansdale, P. L., Cherlin, A. J., \& Kiernan, K. K. (1995). The long-term effects of parental divorce on the mental health of young adults: A developmental perspective. Child Development, 66, 1614-1634.

Cherlin, A. J., Chase-Lansdale, P. L., \& McRae, C. (1998). Effects of parental divorce on mental health throughout the life course. American Sociological Review, 63, 239-249.

Cherlin, A. J., Furstenberg, F. F., Chase-Lansdale, P. L., Kiernan, K. E., Robins, P. K., Morrison, D. R., \& Teitler, J. O. (1991). Longitudinal studies of effects of divorce on children in Great Britain and the United States. Science, 252, 1386-1389.

DiLalla, L. F., \& Gottesman, I. I. (1990). Heterogeneity of causes for delinquency and criminality: Lifespan perspectives. Development and Psychopathology, 1, 339-349.

Doherty, W. J., \& Needle, R. H. (1991). Psychological adjustment and substance use among adolescents before and after a parental divorce. Child Development, 62, 328-337.

Elliott, B. J., \& Richards, M. P. M. (1991). Children and divorce: Educational performance and behaviour before and after parental separation. International Journal of Law and the Family, 5, 258-276.

Emery, R. E. (1999). Marriage, divorce, and children's adjustment (2nd ed.). Thousand Oaks, CA: Sage.

Hindelang, M. J., Hirschi, T., \& Weiss, J. G. (1981). Measuring delinquency. Beverly Hills, CA: Sage.

Huizinga, D., \& Elliott, D. S. (1986). Reassessing the reliability and validity of self-report delinquency measures. Journal of Quantitative Criminology, 2, 293-327.

Jockin, V., McGue, M., \& Lykken, D. (1996). Personality and divorce: A genetic analysis. Journal of Personality and Social Psychology, 71, 288-299.

Lahey, B. B., Hartdagen, S. E., Frick, P. J., McBurnett, K., Connor, R., \& Hynd, G. W. (1988). Conduct disorder: Parsing the confounded relations to parental divorce and antisocial personality. Journal of Abnormal Psychology, 97, 334-337.

McGue, M., \& Lykken, D. T. (1992). Genetic influence on risk of divorce. Psychological Science, 3, 368-373.

McLanahan, S., \& Sandefur, G. (1994). Growing up with a single parent: What helps, what hurts. Cambridge, MA: Harvard University Press.

Moffit, T. E. (1993). Adolescence-limited and lifecourse-persistent antisocial behavior: A developmental taxonomy. Psychological Review, 100, 674-701.

National Center for Health Statistics. (1997). Births and deaths: United States, July 1995-June 1996. Monthly Vital Statistics Report, 45(Suppl. 2), 1-18.

Peterson, J. L., \& Zill, N. (1986). Marital disnuption, parent-child relationships, and behavior problems in children. Journal of Marriage and the Family, 48, 295-307.

Rutter, M. (1971). Parent-child separation: Psycho- 
logical effects on the children. Journal of Child Psychology and Psychiatry, 12, 233-260.

Scarr, S., \& McCartney, K. (1983). How people make their own environments: A theory of genotypeenvironment effects. Child Development, 54, 424 435.

Simons, R. L., \& Chao, W. (1996). Conduct problems. In R. L. Simons (Ed.), Understanding differences between divorced and intact families (pp. 125-143). Thousand Oaks, CA: Sage.

U.S. Bureau of the Census. (1992). Marriage, divorce, and remarriage in the 1990 's. Current Population Reports, 23-180. U.S. Government Printing Office. Wallerstein, J., \& Blakeslee, S. (1989). Second chances: Men, women, and children a decade after divorce. New York: Ticknor \& Fields.

Received August 25, 1998

Revision received June 1, 1999

Accepted June 3, 1999 